\title{
Subsídios para a gestão de jardins botânicos no Brasil - o caso do Jardim Botânico Adolpho Ducke de Manaus
}

\author{
Improving the management of Brazilian botanical gardens: \\ the case of the Adolpho Ducke Botanical Garden of Manaus
}

\author{
Antonia Lucia Fernandes Barroso ${ }^{1,2,3}$ \& Rita de Cássia Guimarães Mesquita ${ }^{1,2}$
}

\begin{abstract}
Resumo
Independente de sua forma de administração, para atingir seus objetivos, os jardins botânicos precisam estar amparados em instrumentos de gestão que orientem as ações a serem implementadas, e traduzam as expectativas e necessidades de seus visitantes em programas e projetos. O estudo se propôs a apresentar subsídios para nortear a gestão do Jardim Botânico Adolpho Ducke de Manaus, baseado na percepção, nas demandas e expectativas através de um levantamento de informações junto aos diferentes atores que se relacionam com o jardim, buscando assegurar o alcance efetivo dos seus objetivos, bem como seu fortalecimento institucional, ponderando suas características peculiares e importância no contexto amazônico. A pergunta central deste estudo é como deverá ser administrado para atender às expectativas e demandas de seus usuários. Para isso foram estabelecidos três objetivos principais, que deverão auxiliar no estabelecimento de uma gestão mais adequada ao jardim. Atualmente, o documento que norteia sua gestão é o seu regimento interno, no qual está estabelecido a sua missão, seus objetivos e estrutura de gestão, sendo este um primeiro norte, contudo ainda falta um instrumento que contemple um planejamento de futuro.
\end{abstract}

Palavras-chaves: gestão, áreas protegidas, jardim botânico.

\begin{abstract}
Regardless of its form of management, to achieve its goals the botanical gardens must be supported by management tools that guide the actions to be implemented, and reflect the expectations and needs of its visitors in programs and projects. The study aimed to provide subsidies to guide the management of the Adolpho Ducke Botanical Garden of Manaus, based on the perception, the demands and expectations through a survey of information from the different stakeholders that interact with the Garden, seeking to ensure the effective achievement of its goals, as well as its institutional strengthening, considering its peculiar characteristics and importance in the Amazonian context. The central question of this study is how the Botanical Garden should be administrated in order to meet the expectations and demands of its users. For that, three main goals were established, which can assist in establishing a better management of the Garden. Currently, the document that guides its management is its bylaws, which establishes its mission, objectives and management structure, being a north, yet there is still a lack of an instrument that includes planning for the future.
\end{abstract}

Key words: management, protected areas, botanical garden.

\section{Introdução}

Jardins Botânicos são espaços importantes para a conservação da flora, apresentando numerosas espécies e variedades de coleções de plantas vivas, mantidas e ordenadas cientificamente, devidamente documentadas e identificadas, com a finalidade de recreação, exposição, educação e pesquisa. Normalmente se caracterizam como uma área delimitada em meio ao espaço urbano, destinada ao cultivo, manutenção, conservação e divulgação de informações sobre a vegetação. Estas áreas são um excelente ambiente para se desenvolver diferentes projetos e pesquisas, destacando a relevância da conservação ambiental nas diferentes áreas como educação, biologia, turismo, artes, história, entre outras, possibilitando a divulgação do conhecimento de espécies de plantas (Rocha \& Cavalheiro 2001).

\footnotetext{
${ }^{12}$ Instituto Nacional de Pesquisa da Amazônia, INPA, Av. André Araújo, 2.936, Petrópolis, 69067-375, Manaus, AM, Brasil.

${ }^{3}$ Autor para correspondência: tonialfb@gmail.com
} 
Inicialmente os jardins e hortos botânicos surgiram para o cultivo de plantas de interesse medicinal, e mais tarde para cultivar plantas de interesse comercial. Datados do século XVI os jardins botânicos mais antigos do mundo tinham a sua história ligada às fundações de medicina $\mathrm{e}$ serviam para fornecer material para os alunos de medicina e farmácia na confecção de medicamentos (Pereira 2006). Se no passado os jardins botânicos estiveram fortemente associados a acadêmicos e pesquisadores, hoje uma multiplicidade de diferentes sujeitos sociais interagem com estes espaços, ampliando as finalidades e a relevância dos jardins no contexto socioambiental em que estão inseridos. Moradores urbanos tem cada vez menos contato com ambientes naturais, o que coloca os jardins botânicos em posição chave para despertar o interesse da sociedade pela natureza. Além disso, desempenham um papel importante ao contribuir para a conservação, classificação, avaliação e utilização sustentável do patrimônio genético vegetal, em especial de espécies raras ou ameaçadas de extinção, bem como desenvolver o respeito a todas as formas de vida (Heywood 1989). Visitar o jardim botânico de uma cidade, além de prazeroso, é instrutivo e educacional, sendo uma alternativa importante para o processo de conscientização ambiental, e tendo um potencial singular no processo de educar (Rodrigues 2005).

A cidade de Manaus, um exemplo de zona urbana desenvolvida no meio da floresta, vem sofrendo com seu processo de expansão desordenada devido ao alto crescimento demográfico nos últimos anos, causando grandes impactos ao meio ambiente (Nogueira et al. 2007). A capital do Amazonas cresce sobre floresta primaria, e já chegou ate a Reserva Ducke, uma área de floresta primaria de 10.000 hectares localizada na porção norte da cidade, recentemente categorizada como unidade de conservação pela Prefeitura de Manaus. Desde 27 de março de 2012, por meio do Decreto $N^{\circ} 1.502$, a Reserva Adolpho Ducke passou a ser considerada uma Área de Proteção Ambiental (APA), que integra as Unidades de Uso Sustentável, na forma do art. 14 da Lei $\mathrm{n}^{\circ} 9.985 / 2000$, destinada a proteger a diversidade biológica, disciplinar o processo de ocupação e assegurar a sustentabilidade do uso dos recursos naturais. Ali fica localizado o Jardim Botânico Adolpho Ducke de Manaus, daqui por diante referido como JB de Manaus, que por sua localização e o fato de se caracterizar como um jardim botânico de conservação in situ, tendo a floresta Amazônica como seu principal acervo, se apresenta como um caminho para o diálogo que aproxima a população de questões ambientais, colaborando com a conservação da biodiversidade e a promoção da sustentabilidade socioambiental.

O JB de Manaus oferece aos seus visitantes um pouco da visão do que é a floresta amazônica, e tem se mostrado o local ideal para que as escolas levem aos jovens, de maneira complementar ao ensino formal, conhecimento sobre a flora e a fauna da região através do contato direto com a natureza. Seu papel junto às escolas é proporcionar contato direto com a realidade ambiental, conscientizar os alunos da importância da preservação do meio ambiente, e em especial sobre o valor da floresta para o bem estar de todos, e instigá-los a refletir sobre a importância da preservação e uso dos recursos naturais. Alguns visitantes têm estabelecido relações mais permanentes, retornando seguidas vezes, e incentivando conhecidos a também visitar. Visitantes utilizam o espaço para realizar cursos, aulas de dança, capoeira, pesquisa, e como ponto de lazer.

Os instrumentos de gestão disponíveis para a gestão de jardins botânicos

Independente de sua forma de administração, para atingir seus objetivos, os jardins botânicos precisam estar amparados em instrumentos de gestão que orientem as ações a serem implementadas, e traduzam as expectativas e necessidades de seus visitantes em programas e projetos. O Manual Técnico Darwin para Jardins Botânicos, afirma que todos os jardins devem ter um plano diretor que abrange uma declaração de missão e um plano mestre apoiado por um programa de metas, (Leadlay \& Greene 1999). A Rede Brasileira de Jardins Botânicos - RBJB orienta que os jardins botânicos implementem um instrumento de planejamento (Plano Diretor), que defina as diretrizes e ações para alcançar seus objetivos e a sua visão de futuro. Atualmente, o único documento que norteia a gestão do JB de Manaus é o seu regimento interno, no qual estão estabelecidos a sua missão, seus objetivos e sua estrutura de gestão. O Regimento interno é um documento que instrui como deve ser a gestão. Contudo ainda falta um instrumento que contemple um planejamento integral. 


\section{Plano diretor}

Para gestão dos jardins botânicos, a RBJB recomenda a implementação de um Plano Diretor, que vem a ser um instrumento de ordenamento do espaço físico do jardim, para controle do seu patrimônio natural e cultural e para o planejamento pela sua administração.

Segundo a definição dada pelo Plano Diretor do Jardim Botânico do Rio de Janeiro (2003), um plano diretor de jardim botânico possibilita nortear as prioridades, as ações e os investimentos públicos e privados, tendo como referências o cumprimento da missão institucional e a preservação dos seus valores científicos, naturais, paisagísticos, arqueológicos e histórico-culturais.

O Plano Diretor de um jardim botânico é composto de propostas de ordenamento das áreas, edificações e instalações da instituição e deve incluir os seguintes tópicos: missão, objetivos primários e secundários, diagnóstico: histórico e legislação, limites e situação fundiária, contexto regional, caracterização da área, propostas de manejo, zoneamento, programa de educação ambiental e uso público, pesquisa e conservação da flora, produção, gestão e captação de recursos, comunicação, entre outros (Lopes 2004).

\section{Planejamento estratégico para jardins} botânicos - um olhar para o futuro

Enquanto os planos diretores incorporam partes da visão de futuro, ao identificar, por exemplo, o local para construção de futuras estruturas físicas, a expansão de novas áreas para uso publico, ou as necessidades de intervenção, seja para restauração, manejo, ou mitigação de impactos projetados de visitação, eles guardam um forte componente espaço-territorial, e um horizonte temporal longo (10 anos ou mais). Já o planejamento estratégico tem mais flexibilidade em sua elaboração, um espaço temporal mais curto ( 2 a 5 anos), e trabalha os ambientes internos e externos do jardim botânico, focando nas ameaças, oportunidades, fragilidades e fortalezas do lugar, sempre trabalhando os aspectos dinâmicos de mudança, e o atingimento de metas claras e bem definidas que são o agente da mudança. Um planejamento estratégico bem feito pode evitar a descontinuidade de ações devido a mudanças políticas ou rotatividade de equipe técnica. Além disso, ajuda os colaboradores a incorporarem o planejamento e metas, além de criar uma visão de futuro de longo prazo, que seja bem difundida e incorporada entre as instituições cogestoras e seus colaboradores, para que todos tenham a mesma visão de onde se quer chegar.

O principio é planejar sobre diversos ângulos antes de agir, evitando desperdícios de esforços e recursos, avaliando as diferentes possibilidades de ação a fim de decidir pelas melhores alternativas. Os objetivos podem ser alcançados com maior facilidade quando o planejamento está bem incorporado na instituição (Chiavenato \& Sapiro 2004).

Segundo Leadlay \& Greene (1999), um planejamento de médio e longo prazo, com objetivos definidos e com metas claras deve traduzir o que exatamente se pretende alcançar, sendo necessário que todos os colaboradores entendam de maneira simples e clara a visão, missão e abrangência, ou área de atuação do jardim. Uma vez definido os objetivos e metas, é necessário que este planejamento leve em consideração as diferentes áreas e programas como coleções, educação, a paisagem do jardim, plano de capacitação e até mesmo um plano comercial. Somado a isso, é preciso montar um plano mais detalhado e de curto prazo (plano de ação ou plano operacional) para alcançar os objetivos e metas de longo prazo. Em um planejamento estratégico, os membros da equipe devem conhecer seu papel na estratégia; o que se espera deles; a definição clara das responsabilidades chaves e tarefas; os objetivos a serem alcançados e como o desempenho será medido.

Mas a construção deste plano precisa necessariamente também atender as demandas externas daqueles que são usuários do território de um jardim botânico, no espaço e no tempo, e estar em sintonia com a missão maior para a qual o jardim botânico foi criado. Visitantes e usuários podem contribuir para a melhoria da administração destas áreas colaborando com sugestões, expressando suas expectativas, e avaliando a qualidade dos serviços oferecidos e as práticas conservacionistas da área protegida (Arantes 2010; Vaz 2010).

Para que um jardim botânico cumpra seus objetivos, é necessário que sua gestão esteja em sintonia com as realidades locais, as demandas e expectativas de seus usuários, e o cumprimento de metas regionais, nacionais e internacionais de conservação do patrimônio natural, da educação, e da pesquisa. No entanto, uma gestão efetiva é desafio constante, e aqui propomos relatar o modelo de gestão atualmente implementado no JB de Manaus, e descrever resultados de um diagnostico rápido efetivado com diferentes grupos de usuários 
da instituição, a fim de subsidiar a discussão sobre o real papel que um jardim botânico desempenha na sociedade.

\section{Breve histórico do JB de Manaus}

Buscando discutir ações mitigadoras relacionadas às consequências da ocupação irregular da Reserva Ducke, que ameaçavam a integridade da área, por ocupações irregulares, os pesquisadores do Instituto Nacional de Pesquisas da Amazônia - INPA, realizaram um seminário interno no final da década de 1990, a fim de discutirem as ações emergenciais para minimizarem o risco de perda das áreas de mata nativa. Inicialmente houve a proposta de criação de uma Unidade de Conservação (UC), mas chegou-se à conclusão que a melhor opção para a área era implantar um jardim botânico com o objetivo de buscar alternativas para conter o avanço da ocupação desordenada e proteger as florestas da região, por meio da educação da população e da conservação da flora (JBADM 2010).

Uma parceria entre a Prefeitura Municipal de Manaus e o INPA, estabeleceu uma área de 500 hectares, a partir dos limites da Reserva Ducke, que é contígua por $10 \mathrm{~km}$, sendo $4 \mathrm{~km}$ na lateral oeste e $6 \mathrm{~km}$ na lateral sul, nascendo assim oficialmente, no dia 24 de outubro de 2000 o JB de Manaus, data que coincide com o aniversário da cidade (JBADM 2010). Sua missão é gerar, promover e divulgar conhecimentos sobre a flora amazônica, seus ecossistemas e suas interações com o meio ambiente, contribuindo para a construção de uma consciência ambiental (Regimento Interno 2010).

No Artigo $2^{\circ}$ do Regimento Interno (2010) são apresentados os objetivos do JB de Manaus que contemplam coleções de exemplares da flora amazônica, pesquisas, educação ambiental, intercâmbio interinstitucional, popularização do conhecimento científico e capacitação, além da conservação florestal.

Além da diversidade natural da área, destacam-se suas coleções temáticas, trilhas abertas na floresta que permitem aos visitantes o contato direto com exemplares da flora amazônica em perfeito estado de conservação. Também são realizadas atividades que visam promover uma reflexão sobre a conservação da biodiversidade e estimular as mudanças de atitudes, em espaços de educação não formal. A expectativa é despertar, incentivar e motivar essa temática na educação formal.
O JB de Manaus, por se tratar de uma área protegida em área urbana, além dos benefícios ambientais diretos, o apoio ao desenvolvimento de pesquisas, de projetos de educação ambiental e de difusão de informações, que desperta o interesse da sociedade para a conservação da Amazônia, serve de ponto turístico para a cidade, campo de pesquisa, além dos benefícios intangíveis como aqueles associados à contemplação da paisagem, entre outros.

\section{A gestão do JB de Manaus}

O JB de Manaus vem sendo administrado desde sua criação em um modelo de gestão participativa ou cogestão, envolvendo o INPA e a Prefeitura Municipal de Manaus, por meio da Secretaria Municipal de Meio Ambiente e Sustentabilidade - SEMMAS. A parceria entre INPA e Prefeitura objetivou a conjugação de esforços no sentido de implementar o jardim botânico, e o termo de cooperação define, entre outros pontos, a competência de cada uma das instituições gestoras e cria um comitê técnico científico responsável pela gestão.

Em 2009, passou a participar da gestão um terceiro parceiro, o Museu da Amazônia - Musa, instituição privada, que por meio de um acordo de cooperação técnica com o Ministério da Ciência, Tecnologia e Inovação - MCTI/INPA, se instala em parte sobreposta à área do JB de Manaus e passa a se inserir nas ações de gestão, enquanto traz entre seus programas a instalação de novas estruturas físicas, e de novos projetos, como um laboratório de audiovisual, uma torre de $40 \mathrm{~m}$ para observação do dossel da floresta, e novos espaços para exposições de divulgação científica. Esta parceria buscou a implantação e consolidação do museu, cabendo ao MCTI/INPA, disponibilizar áreas físicas do seu patrimônio para implantação do mesmo (MUSA 2009).

A participação de uma nova instituição tornou-se um desafio à gestão do JB de Manaus, fortalecendo a proposta de complementar o conjunto de atrativos turísticos e de visitação pública existente no local e principalmente no desenvolvimento de diversos projetos socioambientais, revitalizando a difusão do conhecimento técnico científico à seus visitantes. Contudo, até o momento (agosto de 2014) não existia nenhum acordo formal firmado entre INPA, MUSA e Prefeitura Municipal, passados mais de três anos, que articulasse e integrasse as ações realizadas pelas instituições na gestão, sendo 
necessário um alinhamento muito bem estabelecido e uma boa articulação entre as mesmas para que se possa atingir resultados positivos.

Se de um lado a formalização institucional não aconteceu, de outro lado, na pratica, a integração da gestão foi sendo construída pouco a pouco, no enfrentamento das dificuldades do dia a dia. De acordo com Leadlay \& Greene (1999), cada jardim botânico tem suas peculiaridades, mas diferentes técnicas podem ser usadas para assegurar a construção da visão de um jardim, para que sejam elaboradas ações práticas e planos executáveis. No caso do JB de Manaus, a construção desta visão compartilhada entre as instituições cogestoras é fator determinante para a sobrevivência ou não da instituição.

\section{Metodologia}

Mapeamento político-institucional

O diagnóstico institucional implica em identificar e caracterizar as organizações que atuam em uma determinada região e, também, analisar como estas organizações se relacionam, identificando potencialidades e limites nestas relações. (Santos et al. 2005). O mapeamento institucional é um ponto de partida para a geração de informações para uma proposta de gestão para o JB de Manaus.

Talvez um dos primeiros passos neste mapeamento seja compreender a categoria de conservação à qual o JB de Manaus pertence, e como deve se dar sua gestão, diante da Lei, de 18 de julho de 2000, que instituiu o SNUC. A APA é classificada na categoria de uso direto dos recursos naturais, assim como as Florestas Nacionais, Reservas Extrativistas e as Reservas de Fauna. Nessas áreas são permitidas a ocupação humana e a exploração dos recursos naturais, conforme normas específicas que assegurem a proteção da unidade. Além disso, as APAs destacam-se também como unidades de gestão integradas que buscam traduzir na prática o desafio do desenvolvimento sustentável, procurando harmonizar a conservação e a recuperação ambiental e as necessidades humanas. No território das APAs coexistem áreas urbanas e rurais, privadas e públicas, com suas atividades socioeconômicas e culturais e as terras permanecem sob o domínio privado, não exigindo desapropriação pelo poder público (SNUC 2000).

As APAs, ainda segundo a definição do SNUC (2000), também são consideradas como espaços de planejamento e gestão ambiental de extensas áreas que possuem ecossistemas de importância regional, englobando um ou mais atributos ambientais. Necessitam de um ordenamento territorial orientado para o uso sustentável dos recursos naturais, elaborado por meio de processos participativos da sociedade, que resultem na melhoria da qualidade de vida das comunidades locais.

\section{As demandas e expectativas}

dos visitantes, usuários, colaboradores

e gestores

Com o objetivo de produzir um documento que possa orientar sua gestão, três diferentes questionários foram utilizados, aplicados aos visitantes, funcionários e colaboradores, gestores de outros jardins botânicos vinculados a RBJB, bem como para gestores de outras áreas protegidas da Amazônia. O mapeamento das relações políticas, institucionais e sociais estabelecidas e mantidas pelo JB de Manaus, foi iniciado pelos arquivos de registro da sua administração dos anos de 2010 a 2012.

Percepções, demandas/expectativas e outras sugestões, do ponto de vista dos visitantes, foram obtidas em conversas informais, e outras entrevistas semiestruturadas, com turistas, professores de escolas publicas e universitários, e grupos sociais que usam sua estrutura. Perguntas mais especificas, também voltadas para percepções e demandas, foram aplicadas aos colaboradores por ser um grupo já conhecedor do JB de Manaus. Foram considerados colaboradores os funcionários do INPA, Musa e Prefeitura, os bolsistas, monitores e pesquisadores responsáveis por projetos que atuam no JB de Manaus. Um terceiro questionário, dirigido aos jardins botânicos brasileiros e outras áreas protegidas da Amazônia teve como objetivo reunir informações sobre os instrumentos de gestão e suas atividades, e a maneira com que o JB de Manaus pode interagir com os mesmos.

Além dos questionários aplicados, foi realizada uma consulta aos membros do comitê técnico científico do JB de Manaus a fim de buscar informações sobre a situação atual da gestão, e ainda, identificar os diferentes atores que possuem relação com o mesmo nos últimos três anos. Consultas aos arquivos dos agendamentos de visitantes e solicitações diversas dos anos de 2010 a 2012 também foram realizadas, bem como aos documentos relacionados à gestão - Convênio 002/2005, Termo Aditivo ao Convênio 002/2005 e Regimento Interno - que foram importantes para auxiliar as discussões quanto à situação da gestão atual. 
A pesquisa que embasa este trabalho possui um caráter qualitativo e foi analisada seguindo as etapas de análise de conteúdo adaptadas de Moraes (1994), sendo estas: 1 - classificação em categorias (dos diferentes grupos); 2 - tabulação e interpretação das respostas referentes às percepções, demandas e expectativas, bem como os elementos que diferem e/ou integram os grupos de interesse; 3 - descrição dos resultados, apresentando sínteses das respostas, demonstradas de maneira descritiva e em tabelas e gráficos, bem como citações diretas dos dados originais.

\section{Resultados}

\section{Mapeamento institucional}

\section{do JB de Manaus}

Identificou-se que no período de 2010 a 2012, 290 instituições estabeleceram relação com o JB de Manaus, das quais, $31 \%$ são de ensino público; $16 \%$ de ensino privado; $15 \%$ de grupos sociais; $12 \%$ do poder público; $8 \%$ empresas privadas; $5 \%$ de ensino e pesquisa; $7 \%$ imprensa; $3 \%$ ONGs; 2 $\%$ áreas protegidas e $1 \%$ de fomento.

Representando mais de $50 \%$ das relações institucionais do JB de Manaus, estão as escolas de ensino fundamental e médio da rede pública e particular, as instituições de ensino superior federais, estaduais e particulares. Dentre as escolas levantadas, identificou-se que a maioria delas são de bairros do seu entorno. Dentre as motivações para visitação apresentadas pelas escolas, destacamse aquelas relacionadas a atividades de natureza pedagógica. Este grupo busca ainda receber doações de mudas, participar de eventos, usufruir de passeios e outros. Em seguida, com 15 \% estão os grupos sociais, representados pelos grupos de jovens, associação de moradores, grupos de dança, clube de desbravadores, entre outros, e seus objetivos de interação variam entre utilização do espaço para eventos e visitas de lazer. As organizações do poder público representam $12 \%$, dentre elas estão órgãos do Governo do Estado e do Governo Federal, secretarias estaduais e municipais. Seus objetivos são desde aulas de campo, visitas de grupos de funcionários, utilização do espaço para eventos, entre outros. Com 1\% na representação, mas com grande importância, as organizações de fomento estão ligadas diretamente ao financiamento de bolsas para pesquisas de iniciação cientificas bem como desenvolvimento de projetos, sendo estas principais a Fundação de Amparo à Pesquisa do Estado do Amazonas - FAPEAM e o Conselho
Nacional de Desenvolvimento Científico e Tecnológico (CNPq/MCTI).

As demais organizações estão representadas com $7 \%$ pela imprensa, empresas privadas (3\%), organizações não governamentais (3\%) e áreas protegidas $(2 \%)$.

\section{Percepções, demandas/expectativas}

dos sujeitos que se relacionam

com o JB de Manaus

Foram submetidos 94 questionários a grupos de interesse previamente identificados: estudantes; turistas nacionais; turistas estrangeiros; moradores de Manaus; grupos sociais; professores rede pública; professores universitários; empresas privadas e funcionários e colaboradores. Deste total, 84 questionários foram respondidos.

\section{Percepções dos visitantes}

Pelos resultados, a resposta que vem em mente quando se pensa em jardim botânico é biodiversidade que surge como a principal resposta em todos os grupos ( $34 \%$ das respostas). No item biodiversidade foram incluídos termos afins, como fauna e flora, tendo sido separada a resposta "natureza", representando $12 \%$, por indicar uma atividade diferente, neste caso contemplação ou atividade de possibilitar ao usuário um maior contato com a natureza. $\mathrm{O}$ item pesquisa expressa em $18 \%$ das respostas, inclui laboratório a céu aberto, pesquisa de campo, e outras respostas relacionadas, perceptíveis na maioria dos grupos que fizeram associação da pesquisa científica à ideia de jardim botânico. A maioria dos grupos (79\%) acredita que o JB de Manaus está apto a receber visitantes, mas $32 \%$ sugerem que precisa de melhorias, e $11 \%$ sugerem que com a recente melhoria das instalações, torna o local adequado. Contudo, $14 \%$ acreditam que a infraestrutura não está adequada para receber visitantes.

Quanto à importância do JB de Manaus para a cidade, a conservação/preservação (28\%), a interação com a natureza (23\%), a pesquisa $(13 \%)$ e a educação ambiental (11\%) estiveram entre as principais respostas dadas pelos entrevistados. A conservação e a preservação foram agrupadas por refletirem uma percepção de importância como área protegida. A pesquisa também foi citada como importante, indicando reconhecimento pela geração de conhecimentos proporcionada pelo JB de Manaus ou valorização desta atividade no local. 
Demandas/expectativas dos visitantes

Dentre as demandas, $34 \%$ dos visitantes disseram que gostariam de ver elementos da biodiversidade existente no JB de Manaus durante sua visita. Visitantes apontaram demandas relacionadas à infraestrutura, como a necessidade de um espaço de convivência/ lazer com 14\%, trilhas modernas (trilhas autoguiadas e trilhas suspensas) aparecem em terceiro lugar, com 13\% das respostas. Foram citados ainda a educação ambiental, natureza, apresentações culturais, divulgação científica, guias mais qualificados, lanchonete, restaurante, informações técnicas detalhadas, loja de souvenir, centro de eventos comunitários e outros com percentual menor.

Devido ao grande número de sugestões de melhorias pontuais, "outros" acaba figurando com $23 \%$, por um conjunto de respostas que não estão diretamente relacionadas à infraestrutura, mas apontam outras deficiências. Aí se incluem necessidade do JB de Manaus integrar um roteiro turístico, haver uma maior divulgação para a sociedade, pessoas mais qualificadas para atender o público, ações de educação ambiental, cobrança de taxas, ate a disponibilização de botas de proteção para quem visita e a implementação de um programa de gestão da qualidade.

Educação ambiental, lazer, palestras, cursos e oficinas, aparecem como as principais atividades que o JB de Manaus deveria realizar (17\% das respostas cada). São seguidos de ensino e pesquisa com $11 \%$, turismo de aventura ( $8 \%$ ), atividades na comunidade/escola com $8 \%$ e, atividades culturais (6\%) e jardinagem/plantio de mudas/horticultura com $6 \%$. Ainda, foram agrupados em "outros", respostas como o transporte para as escolas, a possibilidade de visita para deficientes e turismo sustentável, que somaram $4 \%$ das respostas. Os resultados mostram um viés muito forte em educação, capacitação e conhecimento, chegando a $65 \%$ das respostas, e estando provavelmente associado ao perfil dos entrevistados, em sua maioria (31\%) sendo estudantes e professores. Se de um lado isso reflete a composição dos grupos visitantes, também aponta para a necessidade de se compreender melhor as demandas e expectativas de grupos menos representados, nas visitas e neste levantamento.

\section{Percepções dos colaboradores}

Funcionários e colaboradores (27), das instituições gestoras, INPA, MUSA e Prefeitura/ SEMMAS responderam os questionários. Isso inclui profissionais que desenvolvem suas atividades no JB de Manaus, e outros que participam da gestão ou de atividades especificas na condição de contratos temporários, estágios, pesquisa de iniciação cientifica, e pesquisadores orientadores de projetos. Para este grupo o JB de Manaus tem grande importância para a cidade por razão da sua biodiversidade (40\%), seguida da possibilidade de aproximar a população da natureza (18\%). A importância da educação vem em terceiro lugar (15\%). A possibilidade de divulgação de informações da Amazônia também é um item relevante e aparece em $8 \%$ das respostas. Lazer $(7 \%)$, pesquisa $(7 \%)$, beleza cênica $(6 \%)$, turismo (4\%) e o tema cultural (2\%), também figuram nas respostas obtidas.

No conjunto dos colaboradores, as atividades educacionais se destacam (36\%) nas respostas, seguida do envolvimento da comunidade com a natureza (22\%), a divulgação científica e o quadro funcional qualificado também se destacam com $9 \%$.

Para um melhor funcionamento, a melhoria nas instalações aparece com $27 \%$, seguida da gestão (21\%) e aumento e melhor qualificação dos recursos humanos (20\%). Sugestões e recomendações para a melhoria das instalações incluíram: área para visitantes em dias de chuva, melhorar a área de acolhimento dos visitantes, melhor limpeza do ambiente, materiais permanentes mais novos, aperfeiçoar os serviços existentes, melhorar a recepção na entrada, um parque infantil, sinalização das vias de acesso, um sistema de ônibus eficiente (partindo do centro da cidade), retirada dos ônibus na entrada (ônibus de empresas de transporte municipais que estão utilizando a frente do JB de Manaus como garagem), construção de torre de observação e de trilhas autoguiadas.

Para melhorar a gestão foram indicados: melhorar a comunicação entre as instituições gestoras, cogestores com poder de decisão, gestão centralizada em uma única instituição, a continuidade dos projetos em parceria com o Musa, novas parcerias, melhoria na administração, gestão mais participativa que leve em consideração a opinião dos colaboradores, consolidação do comitê técnico científico, consolidação do Regimento Interno, sintonia entre as instituições, inserção da iniciativa privada na gestão e parcerias para manutenção.

Varias recomendações foram feitas, relacionadas aos recursos humanos necessários no JB de Manaus, e incluíram pessoal melhor qualificado, mais recursos humanos, guias 
bilíngues, capacitação de pessoal, equipe mais sólida e permanente, colaboradores comprometidos com a missão, pessoal qualificado para áreas específicas, serviço de guia como opcional não obrigatório. Divulgação (6\%), segurança $(7 \%)$, recursos financeiros $(5 \%)$, paisagismo $(3 \%)$ e troca de experiências também aparecem como indicativos para um melhor funcionamento.

\section{Demandas/expectativas}

dos colaboradores

A melhoria das instalações físicas (78\%) foi o que mais se destacou nas respostas do grupo de colaboradores. Nesta categoria, as respostas agrupadas compreendem: área de lazer; infraestrutura para portadores de necessidades especiais; biblioteca, estacionamento, centro de recepção do visitante, enfermaria, lanchonete/ restaurante, loja de produtos/livraria/souvenir, banheiros/vestiário, laboratório, portaria/ recepção, espaço específico para atividades infantis, área para visitantes em dias de chuva, passarelas suspensas, salas equipadas para atividades técnicas, espaço para uso e cultivo de plantas, área de manutenção e apoio técnico (isolada do público), infraestrutura predial, retirada da pavimentação do pátio (sendo substituído por jardins e canteiros), melhoria de acessibilidade, ter um lugar de informação ao turista, entrada de acesso de visitantes, melhorias na fachada e instalação de mais bebedouros. A sinalização e ampliação das trilhas aparecem com $9 \%$ e o paisagismo do jardim com $4 \%$.

Os colaboradores acreditam que o JB de Manaus deve oferecer, mais oportunidades de capacitação ao público (38\%), a educação ambiental e as atividades ecológicas e florestais $(13 \%)$, seguidas da divulgação científica $(10 \%)$, atividades culturais $(8 \%)$, turismo e lazer $(4 \%)$, pesquisa $(3 \%)$ e outras $(3 \%)$. Muitas respostas demonstram preocupação com sustentabilidade, e praticas ecologicamente corretas, contribuindo para mudanças de atitudes nos usuários. Alguns exemplos: uma cantina ou mesmo um restaurante que pudesse atender os visitantes e os colaboradores, que querem passar o dia no JB de Manaus, oferecendo alimentos ambientalmente saudáveis unindo a saúde humana à ambiental (saladas, comidas orgânicas, sucos de frutas típicas da região). Uma loja também foi citada como uma expectativa, e deveria oferecer produtos relevantes para apreciação dos visitantes, desde chapéu, protetor solar, capa de chuva, livros, CDs, souvenires, guias de identificação de animais e plantas, e outros. Bebedouros instalados em diferentes lugares onde se possa beber diretamente da fonte sem precisar usar copos, a criação de um espaço específico para as atividades com crianças, assim como a manutenção da biblioteca com climatização apropriada e especializada para o publico infantil.

Em relação às instituições consideradas importantes para formalizar parcerias, além de manter as parceiras existentes foram citadas pelo grupo dos colaboradores as instituições de ensino e pesquisa (32\%), instituições do poder público $(24 \%)$, as organizações não governamentais $(14 \%)$, a iniciativa privada $(12 \%)$, organizações de fomento e de apoio técnico, turismo e culturais aparecem com 6,5 e $4 \%$ respectivamente.

\section{Grau de conhecimento e concordância} com a missão do JB de Manaus

Em relação ao ponto de vista de qual deveria ser a missão do JB de Manaus, os colaboradores citaram que a missão deveria continuar a mesma, de valorizar a identidade da flora amazônica, gerando e promovendo conhecimento para a sua conservação in situ. Além de promover, realizar e divulgar as pesquisas sobre a flora da região amazônica, assim como ser referencia nesta temática, através de ordenação e manutenção de coleções botânicas cientificamente catalogadas.

Alguns entrevistados sugeriram determinar claramente as funções e atribuições de cada colaborador e ter um quadro de pessoal suficiente e qualificado para atender todos os tipos de frequentadores e as atividades do próprio jardim, pois a ausência destes fatores dificulta o cumprimento pleno da sua missão.

De acordo com os entrevistados, estariam dentre algumas ações que deveriam compor sua missão: uma educação não formal teórica e pratica sobre temas amazônicos, proporcionando um conhecimento da floresta amazônica através de espaço seguro para a população; pesquisar e difundir os conhecimentos adquiridos a partir das pesquisas realizadas na Reserva Ducke, além de se tornar um centro permanente de educação ambiental com diversas opções para todo tipo de público.

Além de ser um espaço de educação e divulgação de conhecimento, deveria ser responsável pela conservação de espécies vegetais em seu acervo (coleções in situ e ex situ) e utilizar 
este acervo para a educação dos visitantes, tendo um compromisso social com o meio ambiente.

Instrumentos de gestão de outros jardins botânicos brasileiros

e instituições afins

Para levantar os instrumentos de gestão foram enviados 40 questionários para os gestores dos jardins botânicos vinculados a RBJB e a alguns gestores de outras áreas protegidas da Amazônia. Um total de 10 Instituições responderam perguntas relacionadas à natureza da instituição, os instrumentos de gestão utilizados e seu processo de elaboração (Tab. 1).

Melhor instrumento de gestão para jardins botânicos

Nas respostas das instituições que participaram da pesquisa, o plano diretor é um dos instrumentos mais importantes para gestão de um jardim botânico, pois permite que se tenha um diagnóstico detalhado sobre diversos temas, um zoneamento da área e define programas e diretrizes de política que se deve perseguir. Além do plano diretor, se destacou o plano de gestão ou manejo e o planejamento estratégico participativo envolvendo poder público, sociedade, universidade e comunidade científica. Outros instrumentos de gestão apontados incluíram regimento interno, estatutos, e regulamento de uso público. O processo de elaboração destes instrumentos se dá em sua maioria de forma participativa, através de reuniões de suas diretorias, com instituições da sociedade civil e governamentais, seminários com equipe técnica por meio de planejamento estratégico, envolvimento da comunidade do entorno, instituições públicas parceiras, universidades, grupos de trabalho, reuniões anuais, e em alguns casos com contratação de consultoria especializada. Apesar disso, merece nota o fato de que nem todos os instrumentos de gestão reportados pelas instituições que responderam nosso questionário tenham sido construídos com ampla participação social.

Tabela 1 - Instrumentos de gestão das instituições consultadas.

Table 1 - Management regulations and documents from analysed institutions.

\begin{tabular}{|c|c|}
\hline Instituição & Instrumentos de gestão \\
\hline $\begin{array}{l}\text { Museu Paraense Emílio Goeldi - } \\
\text { MPEG }\end{array}$ & $\begin{array}{l}\text { Plano diretor, regimento interno, normas gerais de uso e gerenciamento } \\
\text { das coleções científicas; política de dados de coleções e acervos científicos } \\
\text { biológicos; }\end{array}$ \\
\hline PAREST Sumauma & Plano de gestão e conselho consultivo; \\
\hline $\begin{array}{l}\text { Instituto de Botânica - Jardim Botânico } \\
\text { de São Paulo }\end{array}$ & $\begin{array}{l}\text { Plano diretor do jardim botânico e um plano de manejo do parque estadual } \\
\text { das Fontes do Ipiranga no qual o jardim está inserido }\end{array}$ \\
\hline Jardim Botânico de Brasília & Plano diretor, plano de gestão e regimento interno \\
\hline $\begin{array}{l}\text { Jardim Botânico do Instituto } \\
\text { Agronômico de Campinas - Jardim } \\
\text { Botânico IAC }\end{array}$ & Seu plano diretor vem sendo elaborado e atualizado com reuniões anuais \\
\hline $\begin{array}{l}\text { Bosque Rodrigues Alves - Jardim } \\
\text { Botânico da Amazônia - BRAJBA }\end{array}$ & Plano de gestão \\
\hline $\begin{array}{l}\text { Jardim Botânico de João Pessoa } \\
\text { Benjamim Maranhão - JBBM }\end{array}$ & Plano diretor \\
\hline $\begin{array}{l}\text { Fundação Jardim Botânico de Poços de } \\
\text { Caldas - FJBPC }\end{array}$ & Estatuto e regimento interno \\
\hline Parque Municipal do Mindu & $\begin{array}{l}\text { Conselho consultivo, regulamento de uso público e plano de manejo (ainda } \\
\text { não aprovado pelo conselho) }\end{array}$ \\
\hline $\begin{array}{l}\text { Refúgio da Vida Silvestre Sauim } \\
\text { Castanheiras-RVS Sauim Castanheiras }\end{array}$ & Instrumento de gestão seu planejamento anual \\
\hline
\end{tabular}


Como deve ser um jardim

botânico ideal

Perguntamos aos gestores dos outros jardins botânicos e instituições afins, como deve ser um jardim botânico ideal, e nas respostas obtidas a expectativa dos gestores revela uma preocupação com a infraestrutura do local e os serviços prestados à comunidade. Foi apontado como ideal uma estrutura bem cuidada, com espécies vegetais representativas daquela região, placas interpretativas, além de materiais impressos como mapas, folders, catálogos e exposições, "sem esquecer de programas de acessibilidade". Neste aspecto, foi acrescentado que o ideal é que se tenha recurso para as atividades, equipe multidisciplinar afinada e treinada, e material de divulgação. Pelas respostas recebidas infere-se que um bom instrumento de gestão é imprescindível para a realização de atividades em qualquer unidade de conservação ou em jardins botânicos, pois nele deve estar descrito o seu manejo correto.

Atentos às questões legais, foi mencionado que o jardim botânico deve estar qualificado para atender a todas as exigências do Conselho Nacional do Meio Ambiente-CONAMA. "Assim estaremos inseridos no modelo internacional de jardins botânicos", sentenciou um dos questionados. Referindo-se aos compromissos assumidos pela instituição, um dos gestores destacou que o jardim ideal é aquele que cumpre integralmente sua missão e consegue despertar nos visitantes a consciência ambiental. Com um olhar acadêmico-científico, afirma-se que ideal é aquele que, além de executar pesquisas científicas com a biodiversidade do planeta, ainda utiliza destes conhecimentos para ensinar a população visitante.

A atenção à disponibilização da informação é recorrente. Enquanto é afirmado que "jardim botânico ideal é aquele que possui coleções de plantas vivas cientificamente reconhecidas, organizadas, documentadas e identificadas, desenvolve estudos, pesquisas e torna essas informações acessíveis ao público", é lembrada a necessidade de 'traduzir' as informações para uma linguagem acessível ao público. Alguns meios são apontados para aproximar o público: a promoção da educação ambiental, o incentivo à cultura, o lazer e a conservação do meio ambiente. Não se pode idealizar uma área reserva/parque/jardim. "Temos que levar em consideração toda a população do entorno, bem como, a gama de visitantes que nos procuram com seus próprios ideais. A partir daí, tentar construir/adaptar esses ideais ao nosso Parque". Mesmo destacando aspectos diferentes do que considera um jardim botânico ideal, alguns pontos são comuns, conforme resumiu um dos gestores: "local adequado, representativo do bioma a ser mostrado, com estrutura física e funcionais amplas e capacidade de atendimento à população leiga e técnica".

\section{Interesse de parceria}

com o JB de Manaus

Algumas respostas obtidas dos gestores de outras áreas protegidas, mesmo no caso de jardins botânicos localizados em outros estados do país, foram úteis para indicar o tipo de colaboração e interação possível com o JB de Manaus. Ficou claro o interesse em obter exemplares da biodiversidade amazônica, e em aproximar laços de cooperação técnica para fins de coleta, cultivo e reprodução de plantas amazônicas. Respostas sobre os principais interesses das outras instituições em cooperação incluíram os diferentes intercâmbios, sendo estes: de espécies vivas e herborizadas, de informações botânicas, técnico administrativo, de exemplares para coleções e de germoplasma. As trocas destacadas foram principalmente de plantas, sementes, exsicatas e ainda educação ambiental, atividades, publicações, e outras. Assim como o interesse de cooperação, a troca de experiência também foi mencionada, bem como o desenvolvimento de pesquisa científica.

\section{Discussão}

O JB de Manaus está situado em uma área em expansão da cidade de Manaus, com diversas fragilidades socioambientais, incluindo áreas que necessitam de restauração ambiental, conflitos de uso com a população do entorno, falta de um zoneamento da área e deficiência de recursos humanos e financeiros para atender a todas as demandas existentes.

Contudo um dos maiores desafios é o fato da gestão atual estar sendo realizada com baixo nível de integração entre as instituições cogestoras atuando na área, sujeita às mudanças políticas que geram descontinuidade das ações, e com a ausência de um planejamento de médio e longo prazo, com metas bem estabelecidas ou uma visão de futuro que estejam bem difundidas e incorporadas entre as instituições e seus colaboradores. Apesar de a gestão compartilhada ter seus benefícios, se não for bem planejada, pode ocasionar diversas 
dificuldades. Um dos intuitos dessa integração é assegurar a preservação dos interesses do JB de Manaus. Para tanto, os cogestores precisam interagir para discutir aspectos de melhoria dos serviços oferecidos.

Uma gestão que acontece aleatoriamente ou de curto prazo, ocasiona um esforço muito grande em atender demandas diárias e de maneira ineficaz, o que pode vir a gerar um acúmulo de tarefas em determinados setores, bem como a dificuldade de atender às demandas, gerando desgaste, insatisfação e frustração da equipe. É preciso se pensar e um planejamento com objetivos e metas claras, e que seja incorporado pelas instituições cogestoras, e para isso, é preciso que todos os colaboradores entendam de maneira simples e clara a visão, missão e abrangência, ou área de atuação do jardim.

O mapeamento institucional realizado foi importante para compreender o grande número de instituições que interagem com o JB de Manaus, definir o perfil destes visitantes, e apontar as ações necessárias para atender as expectativas deles. Um diagnóstico institucional é importante para caracterizar as organizações e analisar como estas se relacionam, identificando potencialidades e limites nestas relações (Santos et al. 2005).

As respostas obtidas de visitantes e colaboradores podem orientar ações de gestão especificas, contribuindo na construção de metas e indicadores, e identificando pontos a melhorar, outros que devem ser reforçados, devido à importância atribuída a eles, e ainda novidades que agregariam mais valor aos serviços e experiências oferecidas pelo JB de Manaus. Merece destaque, no caso de um jardim com significante foco na conservação in situ de um ecossistema inteiro, como é o caso do JB de Manaus, a abordagem dos temas relacionados à biodiversidade, e à conservação ambiental, assim como a de sensibilizar a população para a conservação e a divulgação de conhecimentos científicos relacionados à floresta amazônica. A oportunidade de o usuário ter um maior contato com a natureza também confirma o JB de Manaus como um caminho para o diálogo que aproxima a população das questões ambientais, colaborando com a conservação da biodiversidade e a promoção da sustentabilidade socioambiental. Isso também é observado por Arantes (2010) e Vaz (2010) relatando que a maioria dos usuários de uma área protegida, busca experimentar uma ligação mais direta com a natureza para o seu bem estar.
Para os visitantes de maneira geral, o JB de Manaus está bem estruturado para recebê-los, contudo alguns acreditam que ainda são necessárias melhorias na sua infraestrutura. Na categoria de turistas, um destaque pode ser dado à necessidade de haver mais informações disponíveis sobre a flora e uma maior quantidade de trilhas. Os moradores, por outro lado, além dos itens citados, também buscam apresentações culturais, atividades com educação ambiental e lazer. Enquanto para os grupos sociais, uma área para desenvolvimento de atividades de lazer, também citam um centro de eventos comunitários como algo que o grupo gostaria de ver instalado. Isso descreve bem as diferenças de expectativas entre estes grupos de visitante, mostrando que alguns gostariam de ter acesso a serviços e atividades das quais pudessem usufruir de modo rotineiro (caso dos moradores do entorno), enquanto outros buscam obter o maior número de experiências no curto espaço de tempo em que estão no local (e daí a demanda por infraestrutura de acesso a floresta em todos os seus níveis). É interessante aprofundar o entendimento sobre as demandas associadas a atividades culturais, principalmente por parte de moradores, e de grupos sociais específicos, como os jovens, pois estas trazem um novo conjunto de atividades ainda não oferecidas regularmente, e que poderiam compor o quadro de eventos, como apresentações teatrais, musicais, cineclube, exposições fotográficas e artísticas, dentre outros. Também apontam para uma diversificação do acervo a ser mantido e oferecido aos visitantes, que deve ser melhor analisado em estudos futuros.

Em relação à infraestrutura, cada grupo apresentou um conjunto de diferentes sugestões, que apontam para seus objetivos e interesses específicos. Destacam-se, mais trilhas, local adequado para alimentação, identificação das árvores, loja de souvenir, mais atividades de lazer, mais atrações para crianças, melhorias na portaria e na paisagem da frente do JB de Manaus, melhoria nos banheiros, e local adequado para alimentação (lanchonete e restaurante), como importantes itens à qual deve ser dada atenção. Este conjunto de respostas coloca um desafio aos gestores, de priorizar e compreender melhor a natureza das demandas, sendo necessário ainda filtrar aquilo que se alinha ou não com a missão de um jardim botânico, ou com atividades que devem préexistir para justificar a infraestrutura demandada (por exemplo, o caso de uma loja de souvenir, 
que implica a produção de materiais a serem comercializados). Apesar da dificuldade de atender todas as necessidades dos diferentes grupos, as instituições gestoras podem priorizar através de um planejamento de curto e médio prazo as melhorias que podem ter o maior impacto de acordo com o foi sugerido pelos visitantes.

Os visitantes demonstram interesse em se aprofundar nos temas ambientais, e naqueles específicos à missão de um jardim botânico, e refletem isso nas respostas associadas com educação ambiental, que incluem pedidos de palestras, cursos e oficinas, atividades de lazer para a população, que podem de certa forma aproximar a população da floresta e atividades de ensino e pesquisa. Segundo Teramussi (2008), programas de educação ambiental eficazes sensibilizam e criam uma mudança de atitude dos visitantes quanto à necessidade da conservação da natureza e os benefícios que ela traz para todos. Essas ações são consideradas pelos visitantes como os principais fatores positivos, especialmente as atividades relacionadas ao fato de possibilitar à população um maior contato com a natureza, devendo ser um ponto à ser bem estudado e planejado pelas instituições gestoras do JB de Manaus.

Algumas perguntas foram direcionadas especificamente para os colaboradores, devido ao fato destes possuírem um conhecimento diferenciado do mesmo. E eles alertaram sobre pontos relevantes associados à proteção da área. Quanto a importância do JB de Manaus para a cidade, destacou-se a função de conter a invasão da Reserva Ducke, uma vez que a expansão urbana já chegou aos limites da reserva, e hoje o JB de Manaus está na interface imediata entre cidade e floresta. Com o crescimento contínuo da cidade de Manaus, a manutenção desta área protegida é um desafio para a gestão do JB de Manaus, mas pelo fato do mesmo poder apresentar aos seus visitantes espécies de plantas representativas da flora amazônica, sendo uma opção de atividades extraclasse para as escolas, isso pode ser uma importante ferramenta de educação ambiental e, consequentemente na conservação de recursos naturais. O JB de Manaus pode ser um local de ensino e aprendizado formal e informal para a comunidade nas áreas ambientais, sociais e ecológicas. Dessa maneira, a gestão deve levar em consideração a importância da educação ambiental como instrumento de diálogo para aproximar a população da área em questão, e evitando conflitos com a comunidade do entorno, e como principal instrumento nas estratégias de proteção.

Atividades educativas regulares, bem como as atividades nas datas comemorativas (dia da biodiversidade, dia do meio ambiente, dia da Amazonia, etc), foram consideradas pelos colaboradores como sendo as atividades mais positivas. Essas atividades devem receber atenção especial da gestão, uma vez que possuem papel importante na aproximação da comunidade com a natureza, despertando nas pessoas a importância de se manter uma área protegida, auxiliando na consolidação dos objetivos de conservação da área. Também foram consideradas atividades positivas as coleções de plantas representativas da flora amazônica, o contato dos visitantes com flora e fauna local.

Em relação a questões que iriam melhorar o funcionamento do JB de Manaus, em geral, as respostas trataram de aspectos da situação da gestão atual.

Visivelmente os colaboradores consideram a gestão desordenada e que melhoraria através de um gestor que represente as três instituições, sugerindo ainda uma gestão mais participativa que leve em consideração as opiniões dos colaboradores. No Regimento Interno do JB de Manaus, um gerente geral deveria ser nomeado com obrigações definidas estabelecidas, como por exemplo, supervisionar todas as equipes técnicas e administrativas, contudo o mesmo não foi nomeado até o momento (janeiro de 2013). De acordo com Falconi (2009), a liderança é o único agente de mudanças em uma instituição, não adiantando método ou conhecimento técnico se não houver liderança para o fazer acontecer. A implantação e a mudança são indelegáveis e vem por meio da capacitação dos liderados, que é um papel essencial do líder. Acredita-se que deva ser uma meta da gestão a escolha de um coordenador geral para executar suas funções de acordo com o regimento interno do JB de Manaus.

Algumas demandas dos colaboradores foram mais voltadas às necessidades técnicas para auxiliarem no trabalho diário, como salas equipadas para os técnicos desenvolverem melhor as suas atividades, área de apoio técnico isolada da visitação, equipamento para suporte da coleção de vida aquática, vestiários equipados com armários e chuveiros, espaço e material técnico para estudo e pesquisa. Elas mostram que o que acontece nos bastidores de um jardim botânico deve receber 
a mesma atenção que recebem as estruturas de acesso público.

Em relação ao serviço que os colaboradores acreditam que o JB de Manaus deve oferecer, pode citar um maior numero de atividades culturais e lúdicas, mais atividades voltadas para crianças e para a comunidade do entorno, cursos de capacitação para a comunidade sobre a flora amazônica e técnica de sustentabilidade para os problemas que circundam a área, e uma maior divulgação cientifica. Ainda, desenvolver um programa de educação ambiental permanente, para ensinar e sensibilizar a população local sobre a necessidade de conservação da natureza.

Várias atividades sugeridas exigirão uma análise cuidadosa sobre sua adequação aos objetivos de um jardim botânico, e às peculiaridades da área em questão, que devem inclusive levar em conta a própria integridade física dos usuários, e a capacidade da equipe técnica em atender às demandas identificadas. Por se tratar de uma área de floresta primaria ainda conectada à mata continua, com uma representação singular da fauna da região, e sujeita a clima equatorial (chuvas intensas, calor, muita umidade). Assim, levantouse a possibilidade de haver pesquisas orientadas para crianças, atividades de lazer e esporte para a comunidade, espaços com exposições sobre a diversidade cultural da Amazônia. Visitas guiadas em inglês e espanhol com material impresso com mapas e informações de interesse e a formação de guias para atuar em trilhas amazônicas, com caminhadas guiadas, também foram citados como serviços a serem criados ou aprimorados. Citouse a necessidade de investimento na formação e acompanhamento dos monitores, assim como um aumento do quadro de pessoal com integrantes qualificados, comprometidos e motivados com a missão do JB de Manaus, somado à demanda de contratação de pessoas exclusivas para o receptivo. Isso estaria diretamente envolvido com a questão de uma melhor recepção dos visitantes.

A maioria dos colaboradores conseguiu extrair a essência da missão do JB de Manaus, apesar de em geral citarem apenas alguns objetivos ou apenas parte da missão. A missão de uma instituição identifica o propósito básico para o qual se direcionam os esforços, explicitando para que a instituição existe. Apesar da missão estar estabelecida e os colaboradores terem a noção básica dessa missão, é preciso que a mesma seja mais bem difundida entre todos os colaboradores, com o desenvolvimento de atividades visando à sensibilização dos colaboradores para incorporarem a missão como sua.

Segundo Leadlay \& Greene (1999), a equipe precisa entender os planos e individualmente devem conhecer seu papel na estratégia, o que é requerido deles, responsabilidades chave e tarefas, objetivos concordados em serem alcançados, como o desempenho deve ser medido e que tipo de cobranças ou avaliações serão aplicadas.

Levantar os instrumentos de gestão de outros jardins botânicos brasileiros e que outras áreas protegidas estão utilizando, foi útil para subsidiar a própria gestão do JB de Manaus. O plano diretor parece ser o instrumento de gestão mais utilizado, pois enquanto um regimento interno orienta as questões internas como as diretrizes gerais da instituição, as diretrizes de cada área especifica e a descrição das funções, normas e regras gerais de conduta, o plano diretor é que define as diretrizes e ações para alcançar seus objetivos e a sua visão de futuro e ainda poderá conter as propostas de ordenamento da área, edificações e instalações disponíveis para o uso público, os programas de manejo, zoneamento, programa de educação ambiental, bem como, pesquisa e conservação da flora e fauna, gestão, captação de recursos, comunicação, entre outras. O JB de Manaus possui um potencial superior ao que vem sendo desenvolvido atualmente e tendo como referência recomendações elencadas, seu instrumento de gestão deverá conter uma proposta para nortear as instituições gestoras.

De acordo com as instituições entrevistadas, o plano diretor é indicado como o melhor instrumento de gestão para um jardim botânico, permitindo que se tenha um diagnóstico detalhado sobre diversos temas, um zoneamento da área e define programas e diretrizes de política que se deve perseguir. Ainda se destacaram o plano de gestão ou manejo e o planejamento estratégico participativo envolvendo poder público, sociedade, universidade e comunidade científica como sendo importantes instrumentos de gestão para um jardim botânico. Estas orientações oferecem um bom subsídio para a elaboração de um instrumento de gestão para o JB de Manaus, incluindo a questão da forma mais participativa. As recomendações dos seus colaboradores, que neste estudo foi um grupo composto basicamente de funcionários que atuam na instituição e de técnicos voluntários que participam de atividades eventuais, ganham 
importância na medida em que estão embasadas na experiência pratica vivida no dia a dia do JB de Manaus.

Ainda que exista uma relativa rotatividade na equipe técnica, com poucos colaboradores permanecendo por períodos longos, estes colaboradores apresentam um perfil técnico, e assim, eles também devem colaborar e estabelecer uma visão de futuro conjunta, assim como determinar os valores, princípios e metas claras para o JB de Manaus. Ouvi-los é uma forma de melhorar a administração, avaliando a qualidade dos serviços oferecidos. O estabelecimento da visão de futuro é a melhor forma de se trabalhar em conjunto para o alcance de um objetivo comum, buscando dirigir os esforços individuais para os objetivos maiores da instituição.

Nota-se que há interesse das instituições consultadas em cooperação em algumas atividades especificas como força para Região Norte no tocante à rede regional norte de jardins botânicos, projetos em educação ambiental, coleções botânicas, pesquisas conjuntas, intercambio de espécies vivas e herborizadas, desenvolvimento de trabalhos científicos, intercambio de germoplasma, trocas de informações e material botânico, intercambio técnico administrativo e de exemplares para coleções, e outros. Isso vai demandar a definição de políticas institucionais que definam as diretrizes e normas para a concretização destas atividades, facilitando sua realização, e minimizando as dificuldades inerentes à indefinição de procedimentos, interesses e prioridades.

Os resultados obtidos neste estudo são um primeiro passo para o entendimento da inserção do JB de Manaus no meio social que o rodeia, mas muitos outros componentes essenciais para a concretização de um plano diretor, ou mesmo de um planejamento estratégico devem ser levados em conta, e incluídos. É possível que grupos de interesse relevantes estejam pouco representados em nosso estudo, devido a não terem respondido nossas entrevistas, ou não terem sido contatados. Em especial destacamos pesquisadores, profissionais da cultura e das artes, empresas, e instituições públicas com atuação na área ambiental que são usuários do espaço (em especial Polícia ambiental, Ministério Público, Instituto Brasileiro do Meio Ambiente e dos Recursos Naturais Renováveis (IBAMA), Instituto Chico Mendes de Conservação da Biodiversidade (ICMBio), etc). É necessário que se constitua uma equipe técnica para a condução do processo de construção do plano diretor, que se faça um planejamento das etapas, e que se construa coletivamente uma visão de quais programas de gestão deverão receber atenção e ser priorizados. Nossos resultados poderão auxiliar nesta definição, mas não se deve minimizar o valor de uma gestão, que considere o enfoque ecossistêmico, e que seja construída de forma participativa.

\section{Considerações Finais}

O presente trabalho levantou informações para colaborar com a gestão do JB de Manaus, auxiliando as instituições gestoras com subsídios para a elaboração de um plano diretor e planejamento estratégico de médio e longo prazo. Com isso, buscando melhorar os seus resultados, aumentar a integração com a sociedade e outras instituições, criando instrumentos de aprendizagem, visando explorar toda sua potencialidade.

Espera-se que as informações expostas e propostas neste trabalho possam auxiliar o alcance efetivo dos seus objetivos, levando ao seu fortalecimento institucional, ponderando suas características peculiares e sua importância no contexto amazônico.

Com base nas informações levantadas no presente trabalho algumas considerações devem ser priorizadas pelas instituições cogestores, principalmente a necessidade de se construir um planejamento que contemple as principais expectativas dos visitantes, como: elaboração de programas de gestão que contemplem a educação, a estrutura de uso público e a pesquisa científica; ampliação das atividades que dão acesso ao visitante a um maior contato com a natureza; estabelecimento de um novo convênio entre as instituições gestoras, com definição das competências de cada uma de forma clara; ampliação das parcerias atuais e fortalecimento das parcerias existentes (empresas privadas, internacionais, governo, outros jardins botânicos); melhorar o processo de gestão do conhecimento produzido no JB de Manaus, para que esse não seja perdido e possa ter aplicação prática, incluindo a necessidade de melhorar a produção de informações técnicas sobre os acervos botânicos e demais organismos encontrados no JB de Manaus; e criar um programa de capacitação com a oferta de cursos periodicamente, além de criar espaços de apoio pedagógico.

Reforça-se aqui a necessidade da participação social na elaboração do planejamento da gestão, que deve apresentar ações que permitem um envolvimento 
em todas as etapas do seu planejamento, apresentando diretrizes, recomendações e ações estratégicas que tenham o objetivo de facilitar e estimular a gestão integrada, considerando os diferentes objetivos de conservação que o JB Manaus se propõe.

\section{Referências}

Arantes, L. M. 2010. Monografia. Percepção ambiental e perfil dos visitantes do instituto Inhotim. Faculdade Pitágoras, Brumadinho. 46p

Chiavenato, I. \& Sapiro, A. 2004. Planejamento estratégico: fundamentos e aplicações. Campus, Rio de Janeiro. 452p.

Falconi, V. 2009. O verdadeiro poder. Práticas de gestão que conduzem a resultados revolucionários. Ed. INDG, Nova Lima. 159p.

Heywood, V.H. 1989. Estratégias dos jardins botânicos para a conservação. Jardim botânico do Rio de Janeiro, Rio de Janeiro. 69p.

JBRJ - Jardim Botânico do Rio de Janeiro. 2003. Plano diretor do Jardim Botânico do Rio de Janeiro. Instituto Brasileiro de Administração Municipal, Rio de Janeiro. 160p.

JBADM - Jardim Botânico Adolpho Ducke de Manaus. 2010. Regimento interno. Instituto Nacional de Pesquisas da Amazônia - INPA/RE 11/2010. Manaus.

Mesquita, R.C.G.; Sampaio, A.C.; Bueno, C.R.; Mesquita, H.; Monteiro, M.S.; Rodrigues, L.S.; Jakovac, A.C.C.; Barroso, A.L.F.; Ferras, M.R. \& Lima, L.F. (orgs.). 2010. Documento técnico de enquadramento do Jardim Botânico Adolpho Ducke de Manaus. JBADM - Jardim Botânico Adolpho Ducke de Manaus, Manaus. 50p.

Leadlay, E \& Greene, J. 1999. Manual técnico Darwin para jardins botânicos. Instituto de Pesquisas Jardim Botânico do Rio de Janeiro/Rede Brasileira de Jardins Botânicos, Rio de Janeiro. 154p.

Lopes, S.B. 2004. Plano diretor do Jardim Botânico de Porto Alegre. Jardim Botânico de Porto Alegre, Porto Alegre. 100p.
Moraes, R. 1994. Análise de conteúdo: limites e possibilidades. In: Engers, M.E.A. (org). Paradigmas e metodologias de pesquisa em educação. EDIPUCRS, Porto Alegre. Pp. 103-111.

MUSA - Museu da Amazônia. 2009. Acordo de Cooperação MCTI/INPA, UEA e SECT. Museu da Amazônia, Manaus. 4p.

Nogueira, A.C.F.; Sanson, F. \& Pessoa, K. 2007. A expansão urbana e demográfica da cidade de Manaus e seus impactos ambientais. In: Anais do XIII Simpósio Brasileiro de Sensoriamento Remoto. INPE, Florianópolis. Pp. 5427-5434

Pereira, T.S. 2006. O jardim botânico ideal. Rede Brasileira de Jardins Botânicos, Rio de Janeiro. $128 \mathrm{p}$.

Rocha, Y.T. \& Cavalheiro, F. 2001. Aspectos históricos do jardim botânico de São Paulo. Revista Brasileira de Botânica 24: 15.

Rodrigues, M.G.S. 2005. Projetos educativos no Instituto de Pesquisa Jardim Botânico do Rio de Janeiro: uma prática de sensibilização para a conscientização ambiental. Dissertação de Mestrado. Universidade Federal Fluminense, Niterói. 82p.

Santos, A.D.; Mendes, L.S.; Gama, A.M.C.F. \& Aleixo, N. 2005. Mapeamento político-institucional nos municípios do sul do estado do Amazonas. IEB, Brasília. 64p.

SNUC - Sistema Nacional de Unidades de Conservação da Natureza. 2000. Ministerio do Meio Ambiente, Brasília. $18 \mathrm{p}$.

Teramussi, T.M. 2008. Percepção ambiental de estudantes sobre o Parque Ecológico do Tietê. Dissertação de Mestrado. USP, São Paulo. Disponível em <http:// www.teses.usp.br/teses/disponiveis/90/90131/ tde-05052008-132727/pt-br.php>. Acesso em 18 agosto 2014.

Vaz, D.M.S. 2010. Perfil dos visitantes do Parque Natural Municipal do Açude da Concórdia - Valença (RJ). Revista Brasileira de Ecoturismo 3: 109-120. 